\title{
Acceptance of Human Papillomavirus Vaccination and Associated Factors Among Parents of Daughters in Gondar Town, Northwest Ethiopia
}

This article was published in the following Dove Press journal: Cancer Management and Research

\author{
Tsigereda Alene $\mathbb{D}^{\prime}$ \\ Asmamaw Atnafu (D) ${ }^{2}$ \\ Zeleke Abebaw Mekonnen ${ }^{3,4}$ \\ Amare Minyihun $\mathbb{D}^{2}$ \\ 'University of Gondar Specialized \\ Comprehensive Hospital, University of \\ Gondar, Gondar, Ethiopia; ${ }^{2}$ Department \\ of Health System and Policy, Institute of \\ Public Health, College of Medicine and \\ Health Sciences, University of Gondar, \\ Gondar, Ethiopia; ${ }^{3}$ Department of Health \\ Informatics, Institute of Public Health, \\ College of Medicine and Health Sciences, \\ University of Gondar, Gondar, Ethiopia; \\ ${ }^{4}$ Health Systems Directorate, Federal \\ Ministry of Health, Addis Ababa, Ethiopia
}

Correspondence: Amare Minyihun University of Gondar, P.o. Box: 196, Gondar, Ethiopia

Email amarebdr@gmail.com
Background: Cervical cancer is one of the profound threats to women's lives and the fourth most common cancer among women. Ethiopia launched the human papilloma vaccination for the first time, with the support of the Global Alliance for Vaccine and Immunization (GAVI) in 2018. Therefore, the aim of this study was to assess the acceptability of the human papillomavirus vaccine and associated factors among parents of daughters in Gondar town, Northwest Ethiopia.

Methods: A community-based cross-sectional study with a total sample of 946 study participants was conducted in Gondar town from April to May 2019. The study participants were selected using a multistage sampling technique from parents having a daughter of 9-17 years age. Data were collected using an interviewer-administered questionnaire. The data were entered into EpiData version 4.2 and exported to STATA version 14 for analysis. Variables having a p-value of $<0.2$ and $<0.05$ in the bivariable and multivariable logistic regression were considered as a statistically significant factor for the acceptance of HPV vaccination.

Results: A total of 899 study participants with a response rate of $95 \%$ were included in the study. Among participants in this study, $81.3 \%$ with $95 \%$ CI $(78.6,83.7)$ accepted to vaccinate their daughters for HPV vaccination. The acceptance to vaccinate daughters for $\mathrm{HPV}$ vaccination was affected by being from the richest household $[\mathrm{AOR}=3.44,95 \% \mathrm{CI}=$ $(1.97,6.01)]$, good knowledge about cervical cancer $[\mathrm{AOR}=5.49,95 \% \mathrm{CI}=(2.62,11.52)]$, and positive attitude towards HPV vaccination $[\mathrm{AOR}=21.53,95 \% \mathrm{CI}=(11.60,39.96)]$.

Conclusion: The study revealed that the acceptance to human papillomavirus vaccination is high and was significantly associated with the level of knowledge about cervical cancer, the attitude towards HPV vaccination, and the wealth status of the households. Therefore, community education on cervical cancer and its prevention is crucial to increase awareness and acceptance as well.

Keywords: cervical cancer, HPV, acceptance, Gondar town, daughters

\section{Introduction}

Globally, cervical cancer is one of the gravest threats to women's lives and the fourth most common cancer among women. It is estimated that over a million women currently have cervical cancer and up to $70 \%$ of the cases are caused by Human Papilloma Virus (HPV) type 16 and $18 .{ }^{1,2}$ Cervical cancer ranks second in incidence and mortality behind breast cancer in developing countries. ${ }^{2}$ The incidence and mortality in sub-Saharan Africa are among the highest in the world and 
account for over $70 \%$ of the global cervical cancer burden with 70,000 new cases annually. ${ }^{3}$ In Ethiopia, the current estimates indicate that every year 6294 women are diagnosed with cervical cancer and more than three-fourth of them dies from the disease. ${ }^{4}$

Most developed countries have well-organized strategies on organized screening, early detection, and successful treatment of precancerous cervical lesions. HPV vaccination provides an opportunity to low-resource settings to reduce the burden of cervical cancer, thus benefits of the vaccine are restricted to the minority of women who have not been infected yet. ${ }^{5-7}$ Ethiopia launched the HPV vaccine for the first time with the support of the Global Alliance for Vaccine and Immunization (GAVI) in 2018. The vaccine is currently being delivered primarily through a school-based approach to reach all eligible girls. ${ }^{8}$

In Ethiopia, misconceptions about the cause and prevention of cervical cancer are common due to a lack of awareness and health-seeking behavior. Therefore, before the nationwide scale-up of cervical cancer prevention programs, assessment of barriers to acceptance and use of the service through appropriate community-level studies are essential. ${ }^{7,9,10}$

Vaccine hesitancy is complicated and context-specific. Thus hesitancy is caused by individual, group, and discourse influences, yet as any vaccine-specific problems. Every country must take steps to understand the extent and nature of hesitancy at an area level, on an unbroken basis. Consequently, every country ought to develop a strategy to extend acceptance and demand for vaccination, that should embrace current community engagement and trust-building, active hesitancy hindrance, regular national assessments of considerations, and crisis response designing. ${ }^{11,12}$

Though vaccination is an effective way to reduce cervical cancer, people's acceptance of vaccination remains a big challenge in developing countries. ${ }^{13}$ Empirical evidence with related to the willingness of the public to take the vaccine, associated factors, and its importance is not well assessed in many low and middle-income countries (LMICs) which is worse in Ethiopia. Thus, this study aimed to assess the acceptability of the human papillomavirus vaccine and associated factors among parents of daughters in Gondar town, northwest Ethiopia.

\section{Methods}

\section{Study Area and Period}

A community-based cross-sectional study was conducted in Gondar town from April to May 2019. Gondar town is
$727 \mathrm{~km}$ away from Addis Ababa (the capital city of Ethiopia) and it is the capital city of the central Gondar Zone of the Amhara Region. It has six sub-cities with 25 urban and eleven rural kebeles. According to the Gondar town plan commission and Gondar health sector information office total population size was 390,644 , two hospitals, one referral and one private hospital, eight health centers, and fourteen health posts.

\section{Population}

The source population was all parents who had daughters aged 9-17 years old living in Gondar town whereas the study population was all parents who had daughters age between 9-17 years old living in the selected kebeles for this particular study.

\section{Sample Size Determination}

The sample size was calculated by using both single and double population proportion formula. The sample size for the first objective was calculated using a single population proportion formula assuming $95 \%$ confidence interval (CI), $5 \%$ marginal error (d), and 50\% expected acceptance, which yielded the sample size of 384 . The sample size for the second objective was determined by using a double population proportion formula using Epi-Info ${ }^{\mathrm{TM}} 7$ software using the following assumptions: $95 \% \mathrm{CI}$, power of $80 \%$, Exposed unexposed ratio $=1$, and Crude Odds Ratio (COR) of two significantly associated variables ie those parents who always used condoms $(\mathrm{OR}=1.77)$ and who perceived vaccination as acceptable $(\mathrm{OR}=7.91)$ from a cross-sectional study conducted at North Vietnam, ${ }^{14}$ which yields a sample size of 430 . Accordingly, the largest sample was obtained from the second objective, and adding a $10 \%$ non-response rate and multiplied by a design effect of 2, the final sample size for this particular study was 946.

\section{Sampling Procedure}

The study participants were selected using the two-stage sampling technique. At the first stage of sampling, kebeles were stratified by urban and rural with which 5 urban and 3 rural kebeles were selected using a simple random sampling technique. In the second stage, 946 households were selected using a systematic sampling technique. The sample size for each kebele was allocated proportionally to their size. 


\section{Data Collection Procedures}

An interviewer-administered questionnaire was used to collect the data. The questionnaire consists of questions on socio-demographic, economic, knowledge, attitude, and information related factors on the acceptability of the vaccination adapted from different literature. The questionnaire was initially prepared in English and translated into Amharic (national language) and again back to English to check for any inconsistencies. The pilottesting was done out of the study area before the actual data collection by taking a sample of $5 \%$. The reliability test for the data collection tool was checked and revealed the Cronbach alpha value of $0.82,0.78$, and 0.92 for knowledge, attitude, and wealth index respectively. Supplementary File 1

\section{Measurements}

Knowledge of the Participants

Was assessed among the participants about the cervical cancer cause, HPV prevention, and HPV vaccine. It was measured using 16 item knowledge questions and categorized as "Poor knowledge" (0-4 out of 16 items), "Moderate Knowledge" (5-12 out of 16 items), and "good Knowledge" (13-16 out of 16 items).

\section{Attitude}

Was assessed among the participants about cervical cancer prevention, HPV vaccine safety, and effectiveness. It was measured using 12 item questions and categorized as negative ( $0-4$ out of 12 items), neutral (5-8 out of 12 items), and positive (9-12 out of 12 items) attitudes.

\section{Acceptability}

Was analyzed for all respondents using a question "Are you willing to vaccinate your daughter for HPV vaccination which can protect against HPV infection? (options: Yes, No).

\section{Wealth Index}

It was calculated using 30 data items on a household's ownership of selected assets, types of water access, and sanitation facilities and computed by Principal Component Analysis (PCA) and divided into three equal parts (three tiles) as poor, medium, and rich wealth index.

\section{Data Processing and Analysis}

The data were entered into EpiData version 4.2 and exported to STATA version 14 for cleaning, coding, and analysis. It was described using frequencies, percentages, and mean and SD to show the distribution of the outcome variable and associated factors with the outcome of interest. Bivariable and multivariable logistic regression analysis were used to see the association between acceptance to the HPV vaccination and the explanatory variables. Crude Odds Ratio (COR) and Adjusted Odds Ratio (AOR) with their $95 \%$ CIs were used to report the regression analysis outputs.

\section{Results \\ Socio-Demographic Characteristics of the Respondents}

A total of 899 study participants with a response rate of 95\% were included in this study. The mean (SD) age of the respondents were $39( \pm 0.30)$ years and the majority 726 $(80.7 \%)$ were female by sex, $632(70.3 \%)$ were urban by residence, $596(66.3 \%)$ were married by marital status, $430(47.83 \%)$ were unable to read and write by education status, 373 (41.4\%) were housewife by occupation and 749 $(83.3 \%)$ were orthodox christen by religion. The majority of the respondents 239 (26.5\%) had three children. Table 1

\section{Knowledge, Attitude and Acceptability of HPV Vaccination for Their Daughters}

Among participants in this study, 731 (81.3\%) with 95\% CI $(78.6,83.7)$ were willing to vaccinate their daughters for the HPV vaccine. The majority of participants 496 (55.2\%) had information about HPV infection, and only 142 (28.6\%) of the participants were informed by health workers. Additionally, 374 (41.6\%) of the participants have poor knowledge about cervical cancer and its risk factors and the majority of the participants $538(59.9 \%)$ had positive attitudes towards the HPV vaccination. Table 2

\section{Factors Associated with Acceptance of HPV Vaccination for Their Daughters}

In the multivariate logistic regression analysis wealth status, knowledge about cervical cancer, and attitude towards HPV vaccination were significantly associated with acceptance of HPV vaccination at a P-value of $<0.05$. Table 3

The study showed that parents from the richest households were 3.44 times more likely to accept HPV vaccination for their daughters as compared with their counterpart's poorest household $[\mathrm{AOR}=3.44,95 \% \mathrm{CI}=$ $(1.97,6.01)]$. Similarly, parents from the middle wealth status were 2.04 times more likely to accept HPV vaccination for their daughters as compared with those parents 
Table I Socio-Demographic Characteristics of Parents of Daughters in Gondar Town, Northwest Ethiopia, 2019 ( $N=899)$

\begin{tabular}{|c|c|c|}
\hline \multicolumn{2}{|l|}{ Variables } & \multirow{4}{*}{$\begin{array}{l}\text { Number } \\
(\%)\end{array}$} \\
\hline Age in years & $21-29$ years & \\
\hline & $30-39$ years & \\
\hline & $\geq 40$ years & \\
\hline \multirow[t]{2}{*}{ Sex } & Male & $173(19.2)$ \\
\hline & Female & $726(80.2)$ \\
\hline \multirow[t]{2}{*}{ Residence } & Urban & $632(70.3)$ \\
\hline & Rural & $267(29.7)$ \\
\hline \multirow[t]{3}{*}{ Marital status } & Single & $57(6.3)$ \\
\hline & Married & $596(66.3)$ \\
\hline & Divorced & $112(12.46)$ \\
\hline \multirow[t]{2}{*}{ Widowed } & 7I(7.9) & \\
\hline & Separate & $63(7.01)$ \\
\hline \multirow[t]{4}{*}{ Religion } & Orthodox & $749(83.3)$ \\
\hline & Muslim & $99(11)$ \\
\hline & Protestant & $25(2.78)$ \\
\hline & Other & $26(2.89)$ \\
\hline \multirow[t]{3}{*}{ Educational status } & Unable to read and write & $430(47.83)$ \\
\hline & $\begin{array}{l}\text { Primary and secondary } \\
\text { education }\end{array}$ & $226(25.14)$ \\
\hline & Diploma and above & $243(27.03)$ \\
\hline \multirow[t]{6}{*}{ Occupation } & Civil servant & $156(17.3)$ \\
\hline & Self-employers & $115(12.9)$ \\
\hline & Merchant & $137(\mid 5.2)$ \\
\hline & Farmer & $62(6.9)$ \\
\hline & House wife & $373(41.4)$ \\
\hline & Other & $56(6.2)$ \\
\hline \multirow[t]{2}{*}{ Number of children } & Less than or equal to five & 789 (87.76) \\
\hline & Greater than five & $110(12.24)$ \\
\hline Number of & One & $604(67.2)$ \\
\hline daughters & More than one & $295(32.8)$ \\
\hline \multirow[t]{3}{*}{ Wealth status } & Poor & $293(32.6)$ \\
\hline & Medium & $305(34.0)$ \\
\hline & Rich & $30 I(33.4)$ \\
\hline
\end{tabular}

from the poorest households after adjusting for other factors $[\mathrm{AOR}=2.04,95 \% \mathrm{CI}=(1.27,3.27)]$.

Pertaining parent's knowledge about cervical cancer, parents who had good knowledge about cervical cancer and its risk factors were 5.49 times more likely to accept the vaccination than those with poor knowledge $[\mathrm{AOR}=5.49,95 \% \mathrm{CI}=(2.62,11.52)]$. Similarly, parents who had moderate knowledge about cervical cancer and its risk factors were 2.98 times more likely to accept HPV
Table 2 Knowledge, Attitude and Acceptability of HPV Vaccination for Their Daughters Among Parents of Daughters in Gondar Town, Northwest Ethiopia, $2019(n=899)$

\begin{tabular}{|c|c|c|}
\hline Variables & Description & $\begin{array}{l}\text { Number } \\
\text { (\%) }\end{array}$ \\
\hline \multirow[t]{2}{*}{ Information about HPV infection } & Yes & $496(55.2)$ \\
\hline & No & $403(44.8)$ \\
\hline \multirow[t]{7}{*}{ Source of Information $(n=496)$} & Television/ & $250(50.5)$ \\
\hline & Radio & \\
\hline & Health & I42(28.6) \\
\hline & workers & \\
\hline & Social media & $20(4.0)$ \\
\hline & Their friend & $74(14.9)$ \\
\hline & Others & $10(2.0)$ \\
\hline \multirow{9}{*}{$\begin{array}{l}\text { Community perceived trusted } \\
\text { source of information }(n=899)\end{array}$} & Health & $277(30.8)$ \\
\hline & extension & \\
\hline & worker & \\
\hline & Website & $171(19.0)$ \\
\hline & Televission & $272(30.3)$ \\
\hline & Relative/ & $127(14.1)$ \\
\hline & friends/ & \\
\hline & $\begin{array}{l}\text { colleagues } \\
\text { News paper }\end{array}$ & $15(1.7)$ \\
\hline & Radio & $37(4.1)$ \\
\hline \multirow{3}{*}{$\begin{array}{l}\text { Knowledge about cervical cancer and } \\
\text { its risk factors }\end{array}$} & Poor & $374(41.6)$ \\
\hline & Moderate & $335(37.3)$ \\
\hline & Good & $190(21.1)$ \\
\hline \multirow[t]{3}{*}{ Attitude towards HPV vaccination } & Negative & $83(9.2)$ \\
\hline & Neutral & $278(30.9)$ \\
\hline & Positive & $538(59.9)$ \\
\hline \multirow[t]{2}{*}{ Acceptability of the HPV vaccination } & Yes & $731(81.3)$ \\
\hline & No & $168(18.7)$ \\
\hline
\end{tabular}

vaccination than those with poor knowledge $[\mathrm{AOR}=2.98$, $95 \% \mathrm{CI}=(1.78,4.97)]$.

Holding other factors constant, parents who had a positive attitude about the HPV vaccination were 21.53 times more likely to accept HPV vaccination for their daughters than those who had negative attitudes $[\mathrm{AOR}=21.53,95 \% \mathrm{CI}=(11.60,39.96)]$. Besides, Parents who had a neutral attitude about the HPV vaccination were 4.03 times more likely to accept the vaccination for their daughters than those who had negative attitudes $[\mathrm{AOR}=4.03,95 \% \mathrm{CI}=(2.27,7.16)]$.

\section{Discussion}

The study was conducted to assess the acceptability of human papillomavirus vaccination and associated factors 
Table 3 Bivariable and Multivariable Analysis of Factors Associated with the Acceptability of HPV Vaccination Among Parents of Daughters in Gondar Town, Northwest Ethiopia, 2019 ( $n=899)$

\begin{tabular}{|c|c|c|c|c|c|}
\hline \multirow[t]{2}{*}{ Variables } & \multirow[t]{2}{*}{ Category } & \multicolumn{2}{|c|}{$\begin{array}{l}\text { Acceptability of the HPV } \\
\text { Vaccination }\end{array}$} & \multirow[t]{2}{*}{ COR $(95 \% \mathrm{Cl})$} & \multirow[t]{2}{*}{ AOR $(95 \% \mathrm{Cl})$} \\
\hline & & Yes (\%) & No (\%) & & \\
\hline \multirow[t]{3}{*}{ Age } & $21-29$ years & $82(79.6 I)$ & $21(20.39)$ & $1: 00$ & ।:00 \\
\hline & $30-39$ years & $334(84.56)$ & $61(15.44)$ & $1.40(0.80,2.43)$ & I.38(0.7I, 2.69) \\
\hline & $\geq 40$ years & $315(78.55)$ & $86(21.45)$ & $0.93(0.54,1.60)$ & $0.84(0.42,1.68)$ \\
\hline \multirow[t]{2}{*}{ Residence } & Urban & $516(80.50)$ & $125(19.50)$ & $1.21(0.82,1.77)$ & I.34(0.76, 2.39) \\
\hline & Rural & $215(83.33)$ & $43(16.67)$ & 1.00 & 1.00 \\
\hline \multirow[t]{5}{*}{ Marital Status } & Single & $50(87.72)$ & $7(12.28)$ & 1.00 & $\mathrm{I}: 00$ \\
\hline & Married & $482(80.87)$ & $114(19.13)$ & $0.59(0.26,1.33)$ & $0.64(0.24,1.73)$ \\
\hline & Divorced & $94(83.93)$ & $18(16.07)$ & $0.73(0.28,1.86)$ & $0.87(0.28,2.74)$ \\
\hline & Widowed & $53(74.65)$ & $18(25.35)$ & $0.41(0.15,1.07)$ & $0.43(0.13,1.44)$ \\
\hline & Separate & $52(82.54)$ & II (I7.46) & $0.66(0.23,1.84)$ & $0.64(0.19,2.21)$ \\
\hline \multirow[t]{3}{*}{ Educational Status } & Unable to read and write & $353(82.09)$ & $77(17.91)$ & 1.00 & 1:00 \\
\hline & Primary and secondary & $182(80.53)$ & $44(19.47)$ & $0.90(0.59,1.36)$ & $0.66(0.37, \mathrm{I} .15)$ \\
\hline & Diploma and above & $196(80.66)$ & $47(19.34)$ & $0.90(0.60,1.36)$ & $0.37(0.20,0.70)$ \\
\hline \multirow[t]{2}{*}{ Number of daughters } & One & $489(80.96)$ & $115(19.04)$ & 1.00 & $1: 00$ \\
\hline & More than one & $242(82.03)$ & $53(17.97)$ & $1.07(0.74,1.53)$ & $0.90(0.57,1.42)$ \\
\hline \multirow[t]{3}{*}{ Wealth status } & Poor & $203(69.28)$ & $90(30.72)$ & 1.00 & $\mathrm{I}: 00$ \\
\hline & Medium & $254(83.28)$ & $51(16.72)$ & $2.20(1.49,3.26)^{*}$ & $2.04(1.27,3.27)^{*}$ \\
\hline & Rich & $274(91.03)$ & $27(8.97)$ & $4.49(2.82,7.17)^{*}$ & $3.44(1.97,6.01)^{*}$ \\
\hline \multirow[t]{2}{*}{ Information } & Yes & $419(84.48)$ & $77(15.52)$ & 1.00 & 1.00 \\
\hline & No & $312(77.42)$ & $91(22.58)$ & $0.63(0.44,0.88)^{*}$ & I.10(0.65, I.88) \\
\hline \multirow[t]{3}{*}{ Knowledge about cervical cancer } & Poor & $259(69.25)$ & $115(30.75)$ & 1.00 & 1.00 \\
\hline & Moderate & 294(87.76) & $4 I(12.24)$ & $3.18(2.14,4.71)^{*}$ & $2.98(1.78,4.97)^{*}$ \\
\hline & Good & 178(93.68) & $12(6.32)$ & $6.58(3.52,12.29)^{*}$ & $5.49(2.62,11.52)^{*}$ \\
\hline \multirow[t]{3}{*}{ Attitude towards HPV vaccination } & Negative & $34(40.96)$ & $49(59.04)$ & 1.00 & 1.00 \\
\hline & Neutral & $193(69.42)$ & $85(30.58)$ & $3.27(1.97,5.42)^{*}$ & $4.03(2.27,7.16)^{*}$ \\
\hline & Positive & $504(93.68)$ & $34(6.32)$ & $21.36(12.22,37.34)^{*}$ & $21.53(11.60,39.96)^{*}$ \\
\hline
\end{tabular}

Notes: I, reference category; *Signficant at $\mathrm{p}<0.05$ level.

Abbreviations: COR, crude odds ratio; $\mathrm{AOR}$, adjusted odds ratio; $\mathrm{Cl}$, confidence interval.

among parents of daughters in Gondar town. The study showed that the majority of the respondents $731(81.3 \%)$ accepted HPV vaccinations for their daughters and to their close families which is consistent with the previous studies in Ethiopia (79.6\%), ${ }^{15}$ Nigeria $(81.8 \%),{ }^{16}$ and South Africa $(80 \%) .{ }^{17}$ However, several studies conducted in different counties like Tanzania (93.0\%), ${ }^{18}$ Nigeria $(88.9 \%),{ }^{19}$ Malaysia $(87.1 \%),{ }^{20}$ and Honduras $(91.0 \%)^{21}$ have shown higher acceptance level than our finding. The discrepancy could be due to the introduction of a new vaccine program to our study participants which may affect their level of acceptance and information. Moreover, some of the above studies were conducted after the provision of the vaccine and summary of information to participants which can lead to an increased level of acceptance compared to participants without such kind of information and vaccine. On the other hand, previous studies conducted in Ethiopia $(69.3 \%),{ }^{15}$ United Arab Emirate (76.6\%), ${ }^{17}$ and Nigeria $(67.4 \%)^{22}$ have shown a lower level of acceptance to vaccination. This may be due to the study participant's differences in socio-demographic characteristics and the level of information. The previous studies might have less information about the benefits of vaccines and the disease problem which might also due to the study time discrepancy. 
This study also noted that knowledge on cervical cancer was significantly associated with acceptability to the human papillomavirus vaccination. This study finding is consistent with previous studies in Malaysia, ${ }^{20,23}$ Honduras, ${ }^{21}$ UAE, ${ }^{7}$ Europe,${ }^{24}$ and Kenya. ${ }^{25}$ This might also be justified that those who have a better knowledge of cervical cancer risk factors; disease severity and prevention methods will have more attention to know the vaccination and good attitude for the vaccination. Additionally, other findings conducted in Nigeria, ${ }^{22,26}$ Canada $^{27}$ and United Arab Emirates ${ }^{7}$ revealed that the main reason for unwillingness was insufficient knowledge about the HPV vaccinations and fear of the side effect where the common reasons for the refusal were the side effects of the vaccination and lack of knowledge.

This finding also revealed that respondents who had a positive attitude about the HPV vaccination was significant associated with the acceptability of the HPV vaccine. This finding is similar to most other concepts of different findings. ${ }^{3-5}$ This might be due to the fact that the parent acceptability of the HPV vaccine is largely driven by their attitudes and beliefs regarding the vaccine's effectiveness, safety, and ease of access. Additionally, the general beliefs about the HPV vaccine's propensity to cause harm or deliver benefits can determine the parent's routine delay or facilitate their decisions to vaccinate for the vaccine.

The present study indicated that the wealth status of parents had a statistically significant association with the acceptance of the HPV vaccination. This finding is consistent with studies done in Hong Kong ${ }^{28}$ and Vietnam. ${ }^{29,30}$ As an individual became economically wealthy; they may have additional money to be allocated for the promotion of their health in addition to basic needs. Additionally, those parents who had better wealth might have a probability to get an opportunity of mass media like TV, radio, and other sources of information for the HPV vaccinations.

\section{Limitation}

Even though this study lies relatively on a large sample size with a high response rate, due to the cross-sectional nature of the study establishment of a causal relationship could not be possible.

\section{Conclusion}

The study has shown that the acceptance to human papillomavirus vaccination is found to be high and willingness to accept was significantly associated with the level of knowledge of cervical cancer, the attitude towards the vaccination, and the wealth status of the households. Therefore, community education on cervical cancer and its prevention to increase awareness are necessary. Moreover, efforts should be made to enhance the awareness about HPV vaccination through mass media and other health education outlets towards HPV vaccination.

\section{Abbreviations}

CC, Cervical cancer; EPI, Expanded Program on Immunization; GAVI, Global Alliance of Vaccination and Immunization; HPV, Human Papilloma Virus; WHO, World Health Organization.

\section{Data Sharing Statement}

The datasets generated and analyzed during the current study are available from the corresponding author upon reasonable request.

\section{Ethics Approval and Consent to Participate}

This study was conducted in accordance with the Declaration of Helsinki. An ethical clearance letter (Ref No/IPH/180/ 2019) was obtained from the Ethical Review Committee of the Institute of Public Health, College of Medicine and Health Sciences, University of Gondar. A permission letter was also sought from Gondar town authority. Written informed consent was obtained from study participants. To obtain participant's consent; the purpose and importance of the study were explained in the consent form, including the right to withdraw from the study if they face any inconvenience. The name of the respondent was not included in the questionnaire and the confidentiality of the data was protected at all levels.

\section{Acknowledgments}

We deeply express our gratefulness to the University of Gondar for financial support without which this project would have not been possible. Our special thanks and sincere appreciation also goes to the Gondar town health department staffs, the study participants, data collectors, and other individuals or organizations that have participated directly or indirectly in the study.

\section{Author Contributions}

All authors made a significant contribution to the work reported, starting from the conception, study design, execution, acquisition of data, analysis, and interpretation. 
All authors took part in drafting, revising, and final approval of the manuscript version to be published. All authors agreed to be accountable for all aspects of this work.

\section{Funding}

This study was funded by the University of Gondar. The views presented in this article are the author's and do not necessarily express the views of the funding organization. The University of Gondar was not involved in the design of the study, data collection, analysis, or interpretation.

\section{Disclosure}

The authors declare that they have no competing interests for this work.

\section{References}

1. Bruni L, Diaz M, Castellsagué X, et al. Cervical human papillomavirus prevalence in 5 continents: meta-analysis of 1 million women with normal cytological findings. $J$ Infect Dis. 2010;202 (12):1789-1799. doi:10.1086/657321

2. Organization, W.H. Comprehensive Cervical Cancer Control a Guide to Essential Practice. 2014.

3. Ferlay J, Shin HR, Bray F, Forman D, Mathers C, Parkin DM. Estimates of worldwide burden of cancer in 2008: GLOBOCAN 2008. Int J Cancer. 2010;127:2893-2917. doi:10.1002/ijc.25516

4. Ababa A. Federal Democratic Republic of Ethiopia Ministry of Health. Ethiopia: Postnatal Care; 2003.

5. Paavonen J, Jenkins D, Bosch FX, et al. Efficacy of a prophylactic adjuvanted bivalent $\mathrm{L} 1$ virus-like-particle vaccine against infection with human papillomavirus types 16 and 18 in young women: an interim analysis of a phase III double-blind, randomised controlled trial. Lancet. 2007;369(9580):2161-2170. doi:10.1016/S01406736(07)60946-5

6. Stokley S, Curtis CR, Jeyarajah J, et al. Human papillomavirus vaccination coverage among adolescent girls, 2007-2012, and postlicensure vaccine safety monitoring, 2006-2013-United States. MMWR Morb Mortal Wkly Rep. 2013;62(29):591.

7. Saqer A, Ghazal S, Barqawi H, et al. Knowledge and awareness about cervical cancer vaccine (HPV) among parents in Sharjah. Asian Pac J Cancer Prev. 2017;18(5):1237.

8. WHO-Ethiopia. Human papillomavirus vaccine for 14 year old girls. 2018

9. Tesfaye ZT, Gebreyohannes EA, Bhagavathula AS, et al., Awareness and knowledge of human papillomavirus and cervical cancer among female medical and health science students at university of Gondar. American Society of Clinical Oncology; 2017.

10. Birhanu Z, Abdissa A, Belachew T, et al. Health seeking behavior for cervical cancer in Ethiopia: a qualitative study. Int $J$ Equity Health. 2012;11(1):83. doi:10.1186/1475-9276-11-83

11. Lane S, MacDonald NE, Marti M, et al. Vaccine hesitancy around the globe: analysis of three years of WHO/UNICEF Joint Reporting Form data-2015-2017. Vaccine. 2018;36(26):3861-3867. doi:10.1016/j.vaccine.2018.03.063

12. Organization, W.H. Immunization, vaccines and biologicals. June 17, 2020. Available from: https://www.who.int/immunization/pro grammes_systems/vaccine_hesitancy/en/. Accessed September 8, 2020.
13. Perlman S, Wamai RG, Bain PA, et al. Knowledge and awareness of HPV vaccine and acceptability to vaccinate in sub-Saharan Africa: a systematic review. PLoS One. 2014;9(3):e90912. doi:10.1371/journal.pone.0090912

14. Dinh Thu H, Nguyen Thanh H, Hua Thanh T, et al. Mothers' willingness to pay for daughters' HPV vaccine in northern Vietnam. Health Care Women Int. 2018;39(4):450-462. doi:10.1080/ 07399332.2017.1411914

15. Geneti H, Hailu D, Muleta G. Assessment of the knowledge, attitude and acceptability towards human papilloma virus and its vaccine among undergraduate female medical students. Gynecol Obstet. 2016;6(11):1-9. doi:10.4172/2161-0932.1000410

16. Okunade KS, Sunmonu O, Osanyin GE, et al. Knowledge and acceptability of human papillomavirus vaccination among women attending the gynaecological outpatient clinics of a university teaching hospital in Lagos, Nigeria. J Trop Med. 2017;2017:1-6. doi:10.1155/2017/8586459

17. Hoque ME. Acceptability of human papillomavirus vaccination among academics at the University of KwaZulu-Natal, South Africa. S Afr Fam Pract. 2015;57(5):318-321. doi:10.1080/ 20786190.2015.1078157

18. Cunningham MS, Skrastins E, Fitzpatrick R, et al. Cervical cancer screening and HPV vaccine acceptability among rural and urban women in Kilimanjaro Region, Tanzania. BMJ Open. 2015;5(3): e005828. doi:10.1136/bmjopen-2014-005828

19. Ezenwa BN, Balogun MR, Okafor IP. Mothers' human papilloma virus knowledge and willingness to vaccinate their adolescent daughters in Lagos, Nigeria. Int $J$ Womens Health. 2013;5:371. doi:10.2147/IJWH.S44483

20. Ezat SW, Hod R, Mustafa J, et al. National HPV immunisation programme: knowledge and acceptance of mothers attending an obstetrics clinic at a teaching hospital, Kuala Lumpur. Asian Pac J Cancer Prev. 2013;14(5):2991-2999. doi:10.7314/ APJCP.2013.14.5.2991

21. Perkins RB, Langrish SM, Cotton DJ, et al. Maternal support for human papillomavirus vaccination in Honduras. $J$ Womens Health. 2011;20(1):85-90. doi:10.1089/jwh.2009.1919

22. Makwe CC, Anorlu RI. Knowledge of and attitude toward human papillomavirus infection and vaccines among female nurses at a tertiary hospital in Nigeria. Int $J$ Womens Health. 2011;3:313-317. doi:10.2147/IJWH.S22792

23. Jalani FF, Rani MD, Isahak I, et al. Knowledge, attitude and practice of human papillomavirus (HPV) vaccination among secondary school students in rural areas of Negeri Sembilan, Malaysia. Int $J$ Collab Res Intern Med Public Health. 2016;8(6):56.

24. Marty R, Roze S, Bresse X, et al. Estimating the clinical benefits of vaccinating boys and girls against HPV-related diseases in Estimating the clinical benefits of vaccinating boys and girls against HPV-related diseases in Europe. BMC Cancer. 2013;13:10. doi:10.1186/14712407-13-10

25. Vermandere H, Naanyu V, Mabeya H, et al. Determinants of acceptance and subsequent uptake of the HPV vaccine in a cohort in Eldoret, Kenya. PLoS One. 2014;9(10):e109353. doi:10.1371/journal.pone.0109353

26. Bisi-Onyemaechi AI, Chikani UN, Nduagubam O. Reducing incidence of cervical cancer: knowledge and attitudes of caregivers in Nigerian city to human papilloma virus vaccination. Infect Agent Cancer. 2018;13:29. doi:10.1186/s13027-018-0202-9

27. Fernandes R, Potter BK, Little J. Attitudes of undergraduate university women towards HPV vaccination: a cross-sectional study in Ottawa, Canada. BMC Women's Health. 2018;18(1):134. doi:10.1186/s12905-018-0622-0

28. Wong CK, Man KKC, Ip P, et al. Mothers' preferences and willingness to pay for human papillomavirus vaccination for their daughters: a discrete choice experiment in Hong Kong. Value Health. 2018;21(5):622-629. doi:10.1016/j.jval.2017.10.012 
29. Poulos C, Yang J-C, Levin C, et al. Mothers' preferences and willingness to pay for HPV vaccines in Vinh Long Province, Vietnam. Soc Sci Med. 2011;73(2):226-234. doi:10.1016/j. socscimed.2011.05.029
30. Tran BX, Than P, Doan T, et al. Knowledge, attitude, and practice on and willingness to pay for human papillomavirus vaccine: a cross-sectional study in Hanoi, Vietnam. Patient Prefer Adherence. 2018;12:945. doi:10.2147/PPA.S165357

\section{Publish your work in this journal}

Cancer Management and Research is an international, peer-reviewed open access journal focusing on cancer research and the optimal use of preventative and integrated treatment interventions to achieve improved outcomes, enhanced survival and quality of life for the cancer patient.
The manuscript management system is completely online and includes a very quick and fair peer-review system, which is all easy to use. Visit http://www.dovepress.com/testimonials.php to read real quotes from published authors. 